\title{
Use of the Moses Technology to Improve Holmium Laser Lithotripsy Outcomes: A Preclinical Study
}

\author{
Mostafa M. Elhilali, MD, PhD, FRCSC, Shadie Badaan, MD, \\ Ahmed Ibrahim, MD, MSc, ${ }^{1,3}$ and Sero Andonian, MD, MSc, FRSC, FACS ${ }^{1}$
}

\begin{abstract}
Objective: To evaluate in vitro and in vivo effects of Moses technology in Holmium laser and to compare it with the Regular mode in terms of lithotripsy efficiency and laser-tissue interactions.

Methods: The Lumenis ${ }^{\circledR}$ Pulse $^{\mathrm{TM}} \mathrm{P} 120 \mathrm{H}$ holmium laser system together with Moses D/F/L fibers were used to compare the Regular mode with the Moses modes in stone retropulsion by using a high-speed camera, and stone ablation efficiency. In addition, a porcine ureteroscopy model was used to assess stone fragmentation and dusting as well as laser-tissue interaction with the ureteral wall.

Results: After a laser pulse, in vitro stone displacement experiments showed a significant reduction in retropulsion when using the Moses mode. The stone movement was reduced by 50 times at $0.8 \mathrm{~J}$ and $10 \mathrm{~Hz}$ $(p<0.01)$. The pronounced reduction of retropulsion in the Moses mode was clearly observed during fragmentation setting (high energy) and dusting (low energy, high Hz). In addition, stone fragmentation tests showed that the Moses modes resulted in a significantly higher ablation volume when compared with the Regular mode $(160 \%$ higher; $p<0.001)$. In vivo assessment also supported the reduction in retropulsion when treating stones in the porcine kidney. Histological analysis of the porcine ureter after direct lasing in the Moses mode suggested less damage than in the Regular mode.

Conclusions: The Moses technology resulted in more efficient laser lithotripsy, in addition to significantly reduced stone retropulsion, and displayed a margin of safety that may result in a shorter procedural time and safer lithotripsy.
\end{abstract}

Keywords: Holmium-YAG laser, laser lithotripsy, prospective study, preclinical evaluation

\section{Introduction}

$\mathbf{T}$ HE HOLMIUM:YITTRIUM-ALUMINUM-GARNET (Ho:YAG) laser, known as the holmium laser, is a commonly used laser for endourologic procedures, particularly for intracorporeal lithotripsy. ${ }^{1}$ The holmium laser is able to fragment all types of stones. Hence, it is recommended as the gold standard for intra-corporeal lithotripsy for endoscopic management of urinary tract stones. ${ }^{2,3}$ Recently, Lumenis has developed a new technology for the Lumenis Pulse ${ }^{\mathrm{TM}}$ $120 \mathrm{H}$ laser system, where the laser pulse first separates the water, "the Moses effect," and then delivers the remaining energy toward the target stone. Therefore, there is less energy lost and the laser transmission is less dependent on fiber-stone distance. This Moses technology requires both pulse modulation (Moses modes) and the use of specially designed Moses D/F/L fibers.

Moses technology introduces a pulse-shape modulation that optimizes energy delivery through water to the target tissue. The modulation is strongly dependent on the fiber, the pulse regime, and the distance of the fiber from the target. The Moses feature is also optimized for maximum energy delivery at two different fiber-target distances. The first setting, Moses A ("Contact") mode, is optimized for operation at a

${ }^{1}$ Department of Urology, Royal Victoria Hospital, McGill University Health Centre, Montreal, Canada.

${ }^{2}$ Department of Urology, Rambam Health Care Campus, Haifa, Israel.

${ }^{3}$ Department of Urology, Alhussain University Hospital, Al-Azhar University, Cairo, Egypt.

(C) Mostafa M. Elhilali et al. 2017; Published by Mary Ann Liebert, Inc. This is an Open Access article distributed under the terms of the Creative Commons Attribution License, which permits unrestricted use, distribution, and reproduction in any medium, provided the original work is properly cited. Mary Ann Liebert, Inc. offers reprint services for those who want to order professionally produced copies of articles published under the Creative Commons Attribution (CC BY) license. To obtain a price quote, email Reprints@ liebertpub.com. Please include the article's title or DOI, quantity, and delivery destination in your email. 
close distance (around $1 \mathrm{~mm}$ ). The second setting, Moses B ("Distance") mode, is optimized for lithotripsy at a distance (around $2 \mathrm{~mm}$ ). The hypothesis behind the use of the two Moses modes (Moses A and Moses B) is based on clinical scenarios. The two Moses modes were selected according to the working distances in real-life scenarios. The optimization for each distance was done on internal pulse modulation parameters as part of the development of the technology. The urologist can choose the specific Moses mode according to the required working distance: "Moses $\mathrm{A}$ " mode for standard stone fragmentation or dusting and "Moses B" mode when the urologist is forced to laser the stone from a distance (e.g., due to anatomical restrictions), or use the popcorn technique. The aim of the present study was to conduct preclinical experiments investigating the effect of the Moses modes and to compare it with the Regular mode in terms of stone retropulsion, efficiency of stone lithotripsy, and finally, laser-tissue interaction.

\section{Materials and Methods}

The following experiments were done to evaluate and explore possible advantages of the new Moses Technology of the holmium laser using the Lumenis Pulse P120H laser system together with Moses D/F/L fibers (Lumenis, Yokneam, Israel). In all experiments, a comparison was made between Regular and Moses modes by using Moses $200 \mu \mathrm{D} /$ F/L fibers (used during flexible ureteroscopy) and Moses $365 \mu \mathrm{D} / \mathrm{F} / \mathrm{L}$ fibers (used during semi-rigid ureteroscopy). For each laser setting, five repeated measurements were performed. Student's $t$-test was used to compare means. A twotailed $p$-value $<0.05$ was considered significant.

\section{Evaluation of stone retropulsion}

To overcome the subjective evaluation of different physicians, this experiment used round phantom plaster of Paris (gypsum) stones as targets placed on a special vertical jig and a fast camera to capture the effect of the fired laser pulse on the stone (Fig. 1). Due to the retropulsion effect of the fired pulse, the stone moves away from the fiber. The distance of the stone movement is measured by means of frame-to-frame analysis. Measurements were done for several combinations of stone sizes, fiber types, and lasing presets of $0.8 \mathrm{~J}$ at $10 \mathrm{~Hz}$, and $1.5 \mathrm{~J}$ at $10 \mathrm{~Hz}$ to represent stone fragmentation regimes, and $0.5 \mathrm{~J}$ at $50 \mathrm{~Hz}$ to represent stone dusting regimes. Stones of 8 and $6 \mathrm{~mm}$ were used for fragmentation regimes to compare both Regular and Moses modes. Stones of $5 \mathrm{~mm}$ were used for the dusting regime comparison (Fig. 1).

\section{Measurement of stone ablation rate}

This experiment measured the ablated volume of a plaster of Paris stone plate. The stone plate was placed horizontally in a water chamber under a motorized stage holding the fiber. This model has been previously described. ${ }^{4}$ The plate was leveled so that the distance between the fiber tip and the plate was $1 \mathrm{~mm}$ at all points of fiber movement. The cross-sectional area of the ablated groove on the side of the stone was measured, and it was multiplied by the stone length to get the ablated volume of the created fissures. The comparison was done for a fragmentation lasing regime of $0.8 \mathrm{~J}$ at $10 \mathrm{~Hz}$, and a dusting regime of $0.4 \mathrm{~J}$ at $80 \mathrm{~Hz}$ (Fig. 2). To avoid variations in measurements, both Regular and Moses modes were compared by using the same stone plate close to each other.

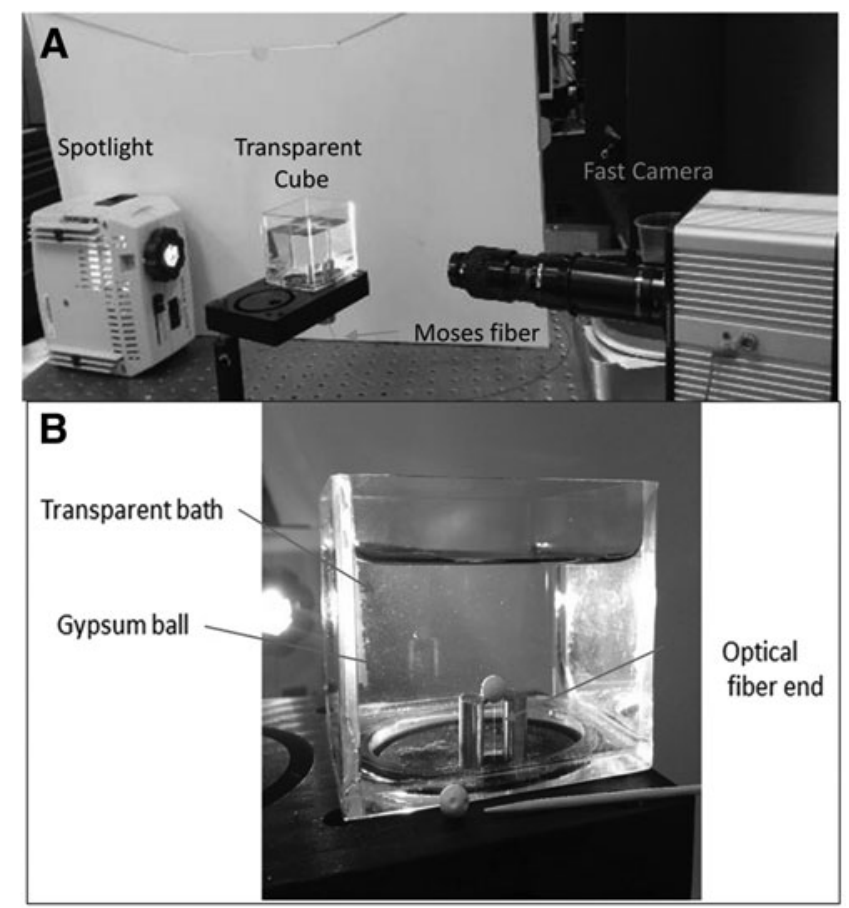

FIG. 1. (A) Set up for fast camera to measure stone retropulsion. (B) Magnified view of the transparent cube by a high-speed camera.

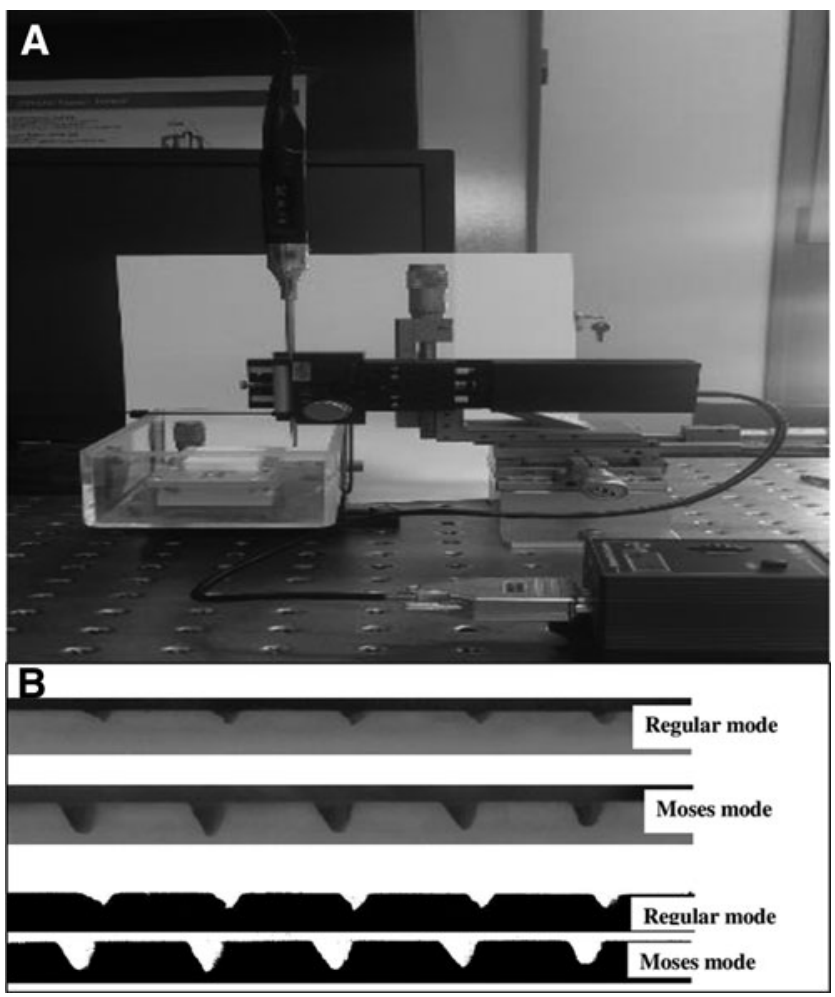

FIG. 2. (A) Experimental setup to measure ablation rate. (B) Representative ablation fissures and digitization for analysis. 
Table 1. Retropulsion Measurement Results

\begin{tabular}{|c|c|c|c|c|c|}
\hline \multirow[b]{2}{*}{ Stone size } & \multicolumn{5}{|c|}{ Stone travel distance } \\
\hline & $\begin{array}{c}\text { Regular } \\
(\text { mean } \pm S D)[\mathrm{mm}]\end{array}$ & $\begin{array}{c}\text { Moses A } \\
\text { (mean } \pm S D)[\mathrm{mm}]\end{array}$ & $\begin{array}{c}\text { Moses B } \\
(\text { mean } \pm S D)[\mathrm{mm}]\end{array}$ & $\mathrm{p}^{\mathrm{a}}$ & $\mathrm{p}^{\mathrm{b}}$ \\
\hline \multicolumn{6}{|c|}{ Lasing regime of $1.5 \mathrm{~J}$ at 10 (fragmentation regime) } \\
\hline \multicolumn{6}{|c|}{ Moses $200 \mathrm{D} / \mathrm{F} / \mathrm{L}$ fiber } \\
\hline $6 \mathrm{~mm}$ & $5.5 \pm 2.6$ & $0.20 \pm 0.14$ & $0.35 \pm 0.31$ & 0.004 & 0.004 \\
\hline $8 \mathrm{~mm}$ & $4.95 \pm 2.3$ & $0.14 \pm 0.04$ & $0.343 \pm 0.28$ & 0.003 & 0.02 \\
\hline \multicolumn{6}{|c|}{ Moses $365 \mathrm{D} / \mathrm{F} / \mathrm{L}$ fiber } \\
\hline $6 \mathrm{~mm}$ & $2.3 \pm 0.85$ & $0.15 \pm 0.09$ & $0.09 \pm 0.15$ & 0.0009 & 0.0009 \\
\hline $8 \mathrm{~mm}$ & $2.58 \pm 0.83$ & $0.116 \pm 0.001$ & $0.1497 \pm 0.057$ & 0.0003 & 0.0003 \\
\hline \multicolumn{6}{|c|}{ Lasing regime of $0.8 \mathrm{~J}$ at 10 (fragmentation regime) } \\
\hline \multicolumn{6}{|c|}{ Moses $200 \mathrm{D} / \mathrm{F} / \mathrm{L}$ fiber } \\
\hline $6 \mathrm{~mm}$ & $5.08 \pm 1.58$ & $0.114 \pm 0.001$ & $0.348 \pm 0.24$ & 0.0002 & 0.0003 \\
\hline $8 \mathrm{~mm}$ & $0.864 \pm 0.58$ & $0.1118 \pm 0.07$ & $0.17 \pm 0.084$ & 0.03 & 0.04 \\
\hline \multicolumn{6}{|c|}{ Moses 365 D/F/L fiber } \\
\hline $6 \mathrm{~mm}$ & $7.314 \pm 2.66$ & $0.157 \pm 0.05$ & $0.457 \pm 0.198$ & 0.0006 & 0.0008 \\
\hline $8 \mathrm{~mm}$ & $1.64 \pm 0.78$ & $0.093 \pm 0.046$ & $0.213 \pm 0.162$ & 0.004 & 0.007 \\
\hline \multicolumn{6}{|c|}{ Lasing regime of $0.5 \mathrm{~J}$ at $50 \mathrm{~Hz}$ (dusting regime) } \\
\hline \multicolumn{6}{|c|}{ Moses $200 \mathrm{D} / \mathrm{F} / \mathrm{L}$ fiber } \\
\hline $5 \mathrm{~mm}$ & $4.92 \pm 3.21$ & $0.23 \pm 0.11$ & $0.086 \pm 0.04$ & 0.03 & 0.01 \\
\hline
\end{tabular}

${ }_{b}^{\mathrm{a}} p$-Values between Regular mode and Moses A mode.

${ }^{\mathrm{b}} p$-Values between Regular mode and Moses B mode.

$\mathrm{SD}=$ standard deviation.

In vivo evaluation

The porcine model allows monitoring advantages and risks of using the Moses technology in an environment mimicking ureteroscopy in humans. Animals were handled according to international guidelines for care and use of laboratory animals. In general, this was an acute (nonsurvival) study that was limited to the assessment of immediate intraoperative effects and parameters.

After obtaining animal ethics approval, the following experiments were performed. After placing animals under general anesthesia, kidney access was achieved after bilateral ureteral catheterization under fluoroscopy. An animal model for flexible ureteroscopy was created by performing laparotomy and making a $2-\mathrm{cm}$ incision through the anterior wall of the proximal ureter. Two to four preprepared artificial round stones (UA 3000 and water 4:1 w/w in weight) measuring $5 \mathrm{~mm}$ in diameter or $3 \times 8 \mathrm{~mm}$ elongated stones were introduced into the lumen of the ureter and advanced into the renal pelvis. At this point, the ureterotomy was closed. After ureteral dilation and insertion of ureteral access sheath, a flexible ureteroscope was introduced for laser lithotripsy. The laser settings used for lithotripsy were $0.8 \mathrm{~J} / 20 \mathrm{~Hz}$ and $1 \mathrm{~J} /$ $10 \mathrm{~Hz}$ for fragmentation and $0.3 \mathrm{~J} / 80 \mathrm{~Hz}$ and $0.4 \mathrm{~J} / 50 \mathrm{~Hz}$ for dusting to compare Regular and Moses modes in a blinded fashion. The operating surgeon provided subjective grading of the degree of retropulsion. Any bleeding or tissue damage caused during the laser lithotripsy was recorded. A total of 19 stones were treated in three pigs.

\section{Laser-tissue interaction and histological analysis}

Different soft tissues were treated by lasing in Regular and Moses modes. Tissues were dissected and sent for histological analysis. Three different lasing areas were prepared and stained with hematoxylin and eosin. Tissue ablation areas and collateral damage margins were analyzed under the microscope at $5 \times$ magnification. The effect on soft tissue was tested in two different settings:

In vivo, the ureteral wall was treated with Regular and Moses modes with the fiber in direct contact with the tissue, providing maximum energy transmission using standard dusting parameters of $0.4 \mathrm{~J} / 50 \mathrm{~Hz}$ and $0.3 \mathrm{~J} / 80 \mathrm{~Hz}$.

In vitro, the bladder wall was treated with Regular and Moses modes with the fiber at a 2 to $2.5 \mathrm{~mm}$ distance from the tissue,

Table 2. Differences in Ablation Volumes Between Regular and Moses Modes

\begin{tabular}{|c|c|c|c|}
\hline & $\begin{array}{c}\text { Fragmentation } \\
(0.8 \mathrm{~J}, 10 \mathrm{~Hz})\end{array}$ & $\begin{array}{c}\text { Dusting } \\
(0.4 \mathrm{~J} \\
80 \mathrm{~Hz})\end{array}$ & $\begin{array}{c}\text { Dusting } \\
(0.5 \mathrm{~J} \\
50 \mathrm{~Hz})\end{array}$ \\
\hline \multicolumn{4}{|c|}{ Fiber Moses 200 D/F/L } \\
\hline $\begin{array}{l}\text { Regular pulse } \\
\text { volume } \\
{\left[\mathrm{mm}^{3}\right]}\end{array}$ & $3.75 \pm 0.30$ & $3.298 \pm 0.45$ & $6.39 \pm 1.21$ \\
\hline $\begin{array}{l}\text { Moses pulse } \\
\text { volume } \\
{\left[\mathrm{mm}^{3}\right]}\end{array}$ & $4.47 \pm 0.30$ & $4.07 \pm 0.23$ & $9.59 \pm 0.66$ \\
\hline $\begin{array}{l}\text { Moses/Regular } \\
\text { ratio }\end{array}$ & 1.19 & 1.23 & 1.50 \\
\hline$p$ & 0.01 & 0.017 & 0.001 \\
\hline \multicolumn{4}{|c|}{ Fiber Moses 365 D/F/L } \\
\hline $\begin{array}{l}\text { Regular pulse } \\
\text { volume } \\
{\left[\mathrm{mm}^{3}\right]}\end{array}$ & $1.68 \pm 0.304$ & $1.79 \pm 0.18$ & $2.99 \pm 0.12$ \\
\hline $\begin{array}{l}\text { Moses pulse } \\
\text { volume } \\
{\left[\mathrm{mm}^{3}\right]}\end{array}$ & $2.26 \pm 0.192$ & $4.65 \pm 0.52$ & $6.66 \pm 0.39$ \\
\hline $\begin{array}{l}\text { Moses/Regular } \\
\text { ratio }\end{array}$ & 1.34 & 2.59 & 2.22 \\
\hline$p$ & 0.01 & $<0.01$ & $<0.01$ \\
\hline
\end{tabular}




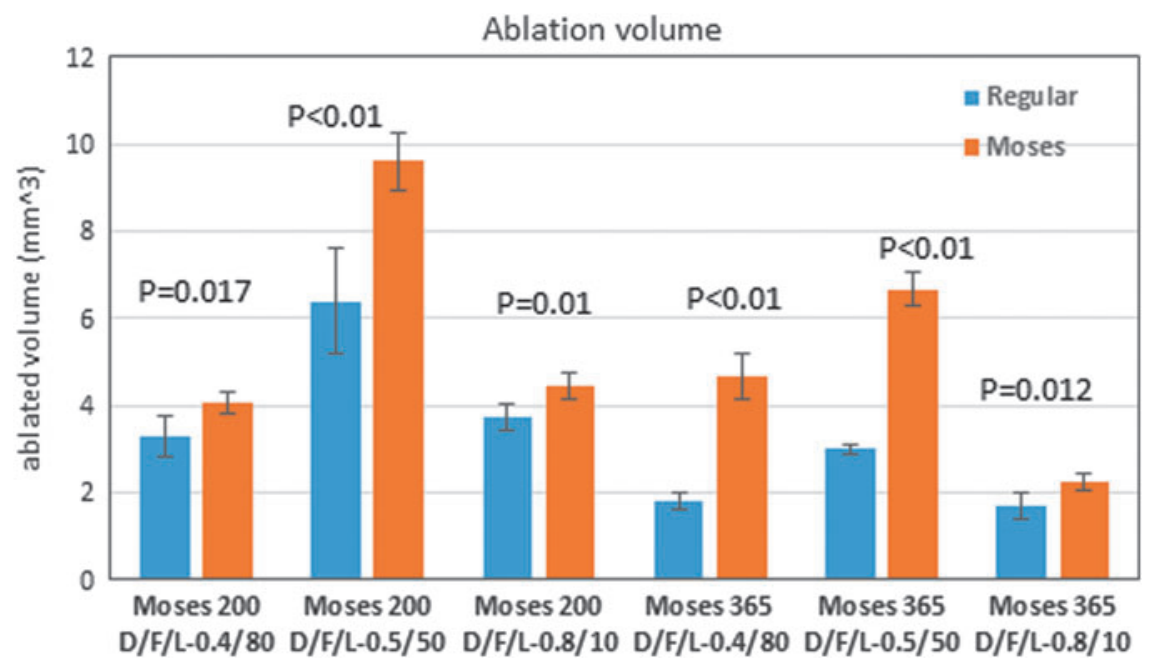

FIG. 3. Differences in stone ablation volumes between Regular and Moses modes.

simulating accidental lasing during lithotripsy. Tests were conducted by lasing at the maximum energy scenario of $5 \mathrm{~J} / 5 \mathrm{~Hz}$.

\section{Fiber flexibility test}

Moses $200 \mathrm{D} / \mathrm{F} / \mathrm{L}$ fiber flexibility was compared with an equivalent $200 \mu$ fiber by using an $8.5 \mathrm{~F}$ flexible ureteroscope (Flex X2; Storz, Tuttlingen, Germany). The difference between the scope maximal deflection angle with and without the laser fiber (deflection loss) was measured by means of a $360^{\circ}$ protractor. For each fiber, deflection loss measurement was repeated five times to detect significance.

\section{Results}

Using Moses modes (A and B) resulted in significantly less stone displacement (retropulsion) when compared with the Regular mode $(p<0.05)$ (Table 1$)$. For stone ablation volumes, in all regimes, the Moses mode resulted in significantly higher ablation volumes when compared with the Regular
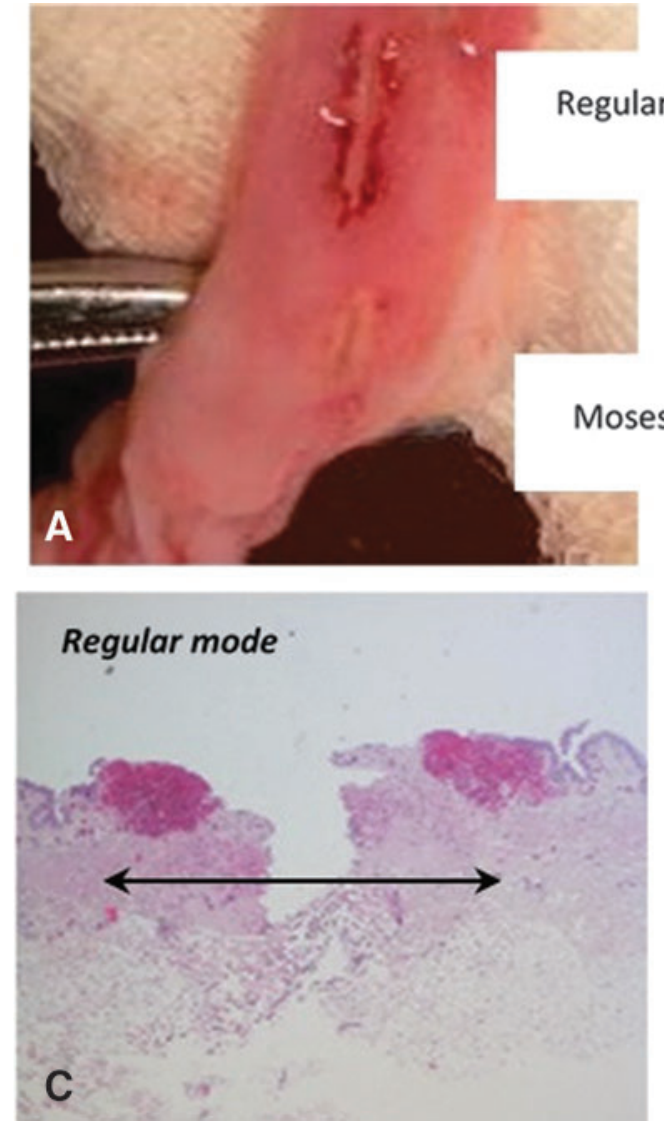
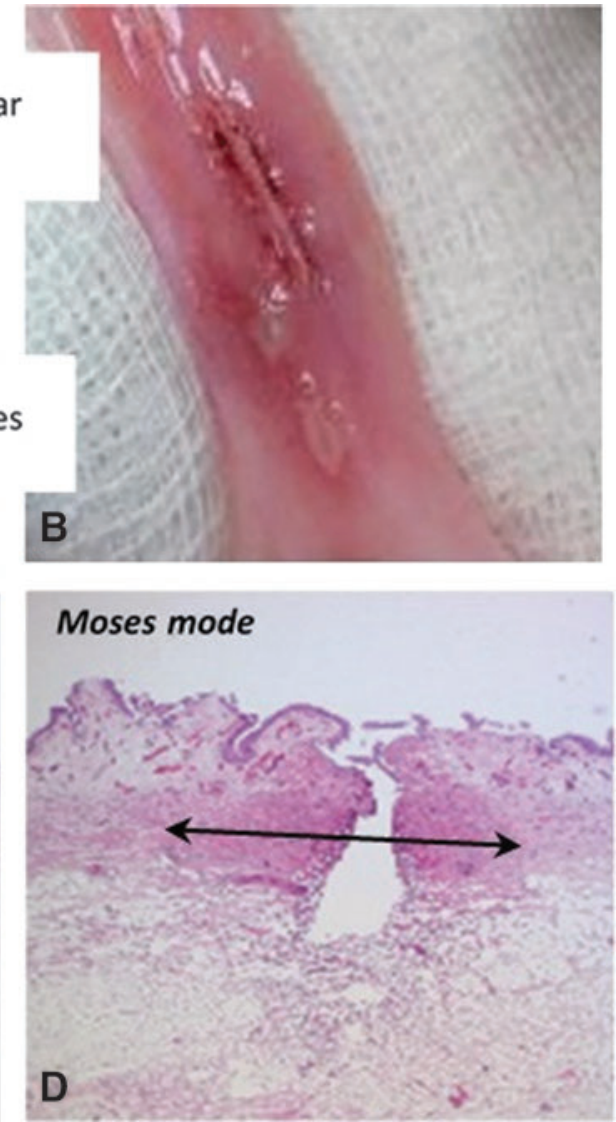

FIG. 4. (A, B) Gross anatomical examination of porcine ureters after contact lasing at a setting of $0.4 \mathrm{~J}$ and $50 \mathrm{~Hz}$. (C, D) Histological examination of porcine ureters after contact lasing at a setting of $0.3 \mathrm{~J}$ and $80 \mathrm{~Hz}$. 

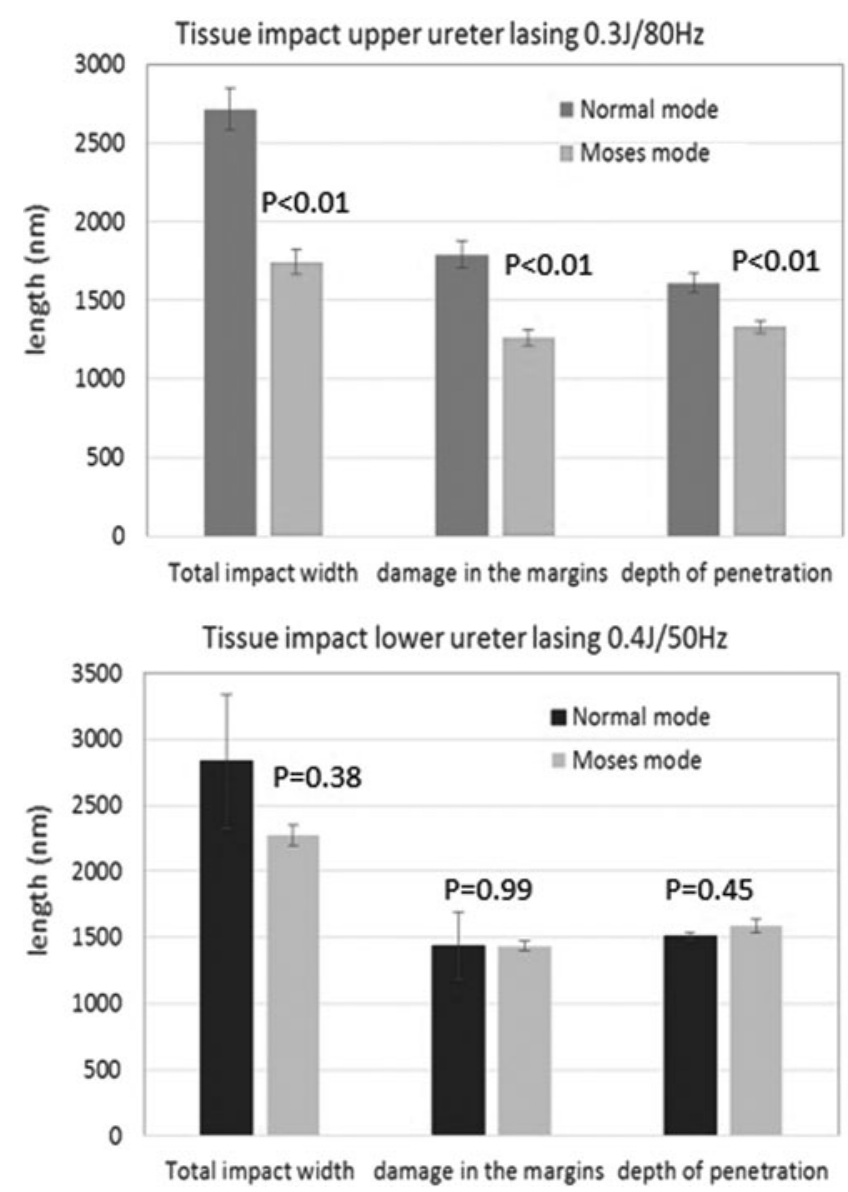

FIG. 5. Differences between Regular and Moses modes in ureteral wall damage resulting from contact lasing.

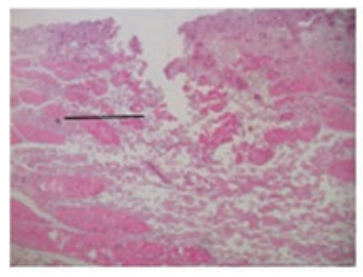

Regular mode

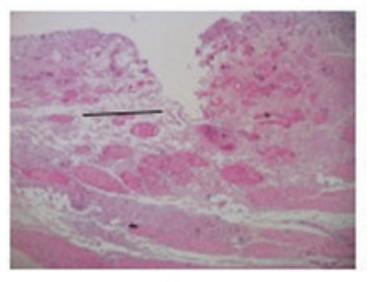

Moses mode

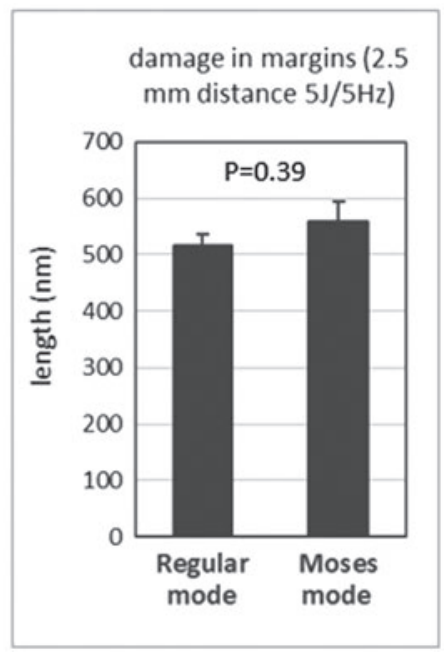

FIG. 6. Both histological images and calculated tissue impact areas showed no significant differences between Regular and Moses modes. Lasing at 2 to $2.5 \mathrm{~mm}$ distance showed no increased risk of ureteral perforation with the Moses mode. mode $(p<0.02)$ (Table 2 and Fig. 3). The difference was greater when using low energy with high frequencies (stone dusting regimes) together with larger diameter fibers (Table 2 and Fig. 3).

During in vivo experiments, the operating surgeon noticed a significant reduction in retropulsion when using the Moses modes. Due to such differences in retropulsion, it was not possible to blind the operating surgeon to the mode. No special adverse events were observed due to laser operation. Moreover, no significant bleeding was observed after lasertissue interaction by using both modes. However, in this model, there were no significant differences in terms of lasing and procedural times between Regular and Moses modes. Average lasing times were $4.45 \pm 1.5$ and $5.17 \pm 2.0$ minutes for Regular and Moses modes, respectively $(p=0.46)$. Average procedural times were $13.20 \pm 4.7$ and $11.92 \pm 4.5$ minutes for Regular and Moses modes, respectively $(p=0.61)$. Due to variability and the limited number of tested stones, it was impossible to measure differences in fragmentation efficiency between the two modes.

Macroscopic analysis of the ureteral tissue revealed that the Moses modes induced a different ablation pattern than the Regular mode. With the Moses modes, there was a reduction in the coagulation pattern in the margins of the ablated tissue, leading to a more concise and narrow incision pattern (Fig. 4). Tissue sections were analyzed to determine the overall tissue damage after lasing by using Regular $v s$ Moses modes, and the average damage was calculated for each mode. For each mode, nine different sections from three different areas of the laser cut were used to calculate the means. While using the settings of $0.3 \mathrm{~J} / 80 \mathrm{~Hz}$, the Moses modes resulted in significantly less total impact width, damage in the margins, and depth of penetration $(p<0.05)$. However, at a setting of $0.4 \mathrm{~J} / 50 \mathrm{~Hz}$, there were no significant differences in the tissue damage parameters tested (Fig. 5).

Regarding the ex vivo treatment of bladder tissue by using $5 \mathrm{~J} / 5 \mathrm{~Hz}$ at a $2.5 \mathrm{~mm}$ distance, both histological images and

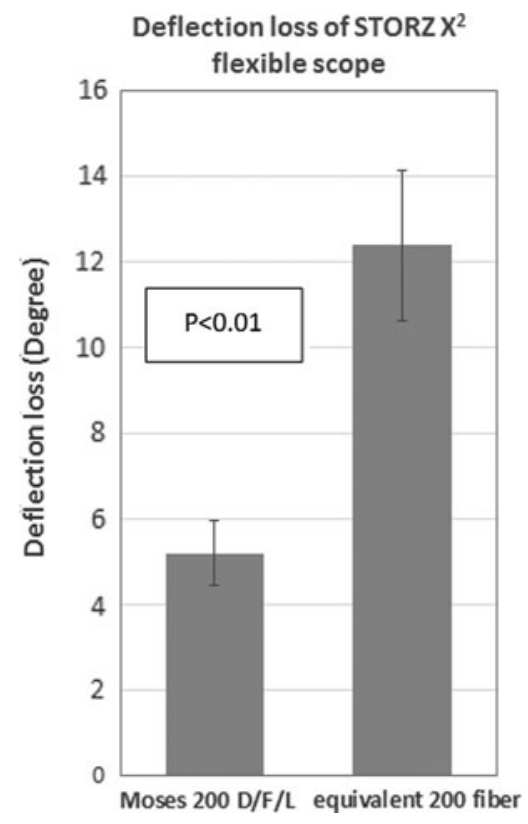

FIG. 7. Fiber flexibility test. 
calculated tissue impact areas showed no significant differences between the Regular and Moses modes. Lasing at a 2 to $2.5 \mathrm{~mm}$ distance showed no increased risk of perforation with the Moses modes when compared with the Regular mode (Fig. 6).

The fiber flexibility test demonstrated a significantly higher flexibility of the Moses $200 \mathrm{D} / \mathrm{F} / \mathrm{L}$ fibers when compared with its equivalent $200 \mu$ fiber by using an $8.5 \mathrm{~F}$ flexible ureteroscope $(p<0.01)$ (Fig. 7).

\section{Discussion}

The wavelength of holmium laser is $2120 \mathrm{~nm}$, which is near the absorption peak of water $(1910 \mathrm{~nm})$. Therefore, the holmium wavelength is strongly absorbed in water. Stones contain enough water that can absorb laser energy, leading to their fragmentation. The absorption of the laser energy in water creates a short-lived vapor bubble, which collapses at the end of the laser pulse. The amount of energy needed for bubble formation is provided at the expense of the pulse energy created by the laser, and the rest of the energy is delivered to the target. ${ }^{1,5-7}$ Recently, Lumenis introduced the "Moses technology," which is a novel holmium laser pulse modulation in the Lumenis Pulse $120 \mathrm{H}$ system delivered through the Moses $\mathrm{D} / \mathrm{F} / \mathrm{L}$ fibers. This new technology enables emission of a controlled portion of energy to create a vapor bubble (known as "Moses effect"), while leaving a portion that travels through the bubble to the stone, thus optimizing the energy delivery through water to the target tissue. The pulse form is strongly dependent on the fiber size, the pulse regime, and the distance between the fiber and the target.

In the present study, the Moses modes resulted in significantly less stone retropulsion when compared with the Regular mode (Table 1). This was more obvious for fragmentation regimes with larger diameter fibers (Moses 365 D/F/L fiber). Stone retropulsion depends on stone size and laser regime, where smaller stones and higher energies are associated with greater retropulsion. ${ }^{8}$ Dusting regimes with lower energies at high frequencies produced less retropulsion for larger stones, but it becomes very apparent again, as the stone size decreases. For all regimes, the Moses modes resulted in significantly less retropulsion when compared with the Regular mode. The reduced retropulsion associated with the Moses modes would be beneficial during ureteral stone holmium laser fragmentation since the Moses modes would decrease the chance of ureteral stone migration into the kidney. In addition, reduced retropulsion could result in an improved efficiency of lithotripsy since the stones move less while using the Moses modes. Furthermore, the significantly more flexible Moses 200 D/F/L fibers resulting in improved flexible ureteroscope deflection (Fig. 7) are expected to enhance the ability of flexible ureteroscopes to treat stones in challenging locations such as those found in the lower pole. Previously, Lee and colleagues demonstrated that retropulsion might be reduced with longer pulse duration without affecting fragmentation efficiency in an in vitro ureteral model. ${ }^{9}$ However, in the present study, this was not compared with the Moses modes.

With regard to stone ablation efficiency, our experiments revealed that the Moses modes significantly improved stone fragmentation characteristics in all tested regimes (Table 2 and Fig. 3). The effect is more pronounced when using lowenergy regimes (e.g., dusting) and larger diameter fibers.
These results are closely matched with the theoretical expectations based on the improved energy delivery of the Moses pulse. Our results are partially in agreement with those reported by Kronenberg and Traxer in their in vitro study showing that low-frequency, high-pulse energy settings were more ablative than high-frequency, low-pulse energy at the same power levels. ${ }^{4}$

Regarding safety and laser-tissue interaction, it was found that using the Moses modes together with the Moses D/F/L fibers did not result in excess damage to ureteral tissue after direct (contact) or indirect (at a distance of 2-2.5 mm) lasing compared with the Regular mode. Moreover, using Moses modes may result in a more concise tissue incision (narrow and precise) when compared with the Regular mode, suggesting reduced potential to collateral tissue damage (Fig. 4). The reduced collateral coagulation damage around the ablation area and in the lateral margins suggested that this new Moses mode is safe.

The limitation of the present study is the lack of evidence regarding clinical evaluation of the Moses technology in the management of urinary tract stones. The clinical evaluation of the Moses mode is currently underway. Moreover, the present study tested stone retropulsion with a specific type of stone. Therefore, not all stone compositions were tested. This was done to avoid variations related to stone composition, resulting in confounding results. Nevertheless, the present study provides the first detailed preclinical evaluation of the Moses technology with regards to stone retropulsion and ablation volumes, in addition to laser-tissue interactions in both in vitro and in vivo settings using the same laser settings used in clinical practice.

\section{Conclusions}

The Moses technology resulted in more efficient laser lithotripsy and showed a significant reduction in stone retropulsion, in addition to an acceptable margin of safety without an increase in tissue damage after direct or indirect lasing compared with the conventional Regular mode. Future clinical studies are needed to further investigate the effects of the Moses mode on the fragmentation efficiency of stones and the potential collateral damage to tissues that are close to stones.

\section{Author Disclosure Statement}

No competing financial interests exist.

\section{References}

1. Zarrabi A, Gross AJ. The evolution of lasers in urology. Ther Adv Urol 2011;3:81-89.

2. Turk C, Petrik A, Sarica K, et al. EAU guidelines on interventional treatment for urolithiasis. Eur Urol 2016;69:475482.

3. Ordon M, Andonian S, Blew B, et al. CUA Guideline: Management of ureteral calculi. Can Urol Assoc J 2015;9: E837-E851.

4. Kronenberg P, Traxer O. In vitro fragmentation efficiency of holmium: yttrium-aluminum-garnet (YAG) laser lithotripsy: A comprehensive study encompassing different frequencies, pulse energies, total power levels and laser fiber diameters. BJU Int 2014;114:261-267. 
5. Khoder WY, Bader M, Sroka R, et al. Efficacy and safety of Ho:YAG laser lithotripsy for ureteroscopic removal of proximal and distal ureteral calculi. BMC Urol 2014;14:62.

6. Teichmann HO, Herrmann TR. Technical aspects of lasers in urology. World J Urol 2007;25:221-225.

7. Zhang JJ, Rajabhandharaks D, Xuan JR, et al. Water content contribution in calculus phantom ablation during Q-switched Tm:YAG laser lithotripsy. J Biomed Opt 2015;20:128001128005.

8. Sea J, Jonat LM, Chew BH, et al. Optimal power settings for Holmium:YAG lithotripsy. J Urol 2012;187:914-919.

9. Lee HJ, Box GN, Abraham JB, et al. In vitro evaluation of nitinol urological retrieval coil and ureteral occlusion device: Retropulsion and holmium laser fragmentation efficiency. J Urol 2008;180:969-973.
Address correspondence to: Mostafa M. Elhilali, MD, PhD, FRCSC Department of Urology Royal Victoria Hospital McGill University Health Centre 1001 Boulevard Decarie, D05.5327 Montreal H4A $3 J 1$

Canada

E-mail: mostafa.elhilali@muhc.mcgill.ca

\section{Abbreviation Used}

$\mathrm{SD}=$ standard deviation 